\title{
Support to Primary Health Care in Transitional Situations: Lessons Learned from the Field
}

\author{
Stéphane Du Mortier ${ }^{*}, 1$, Ruth Bullen ${ }^{2}$ and Hervé le Guillouzic ${ }^{3}$ \\ ${ }^{I}$ International Committee of the Red Cross (ICRC), Geneva \\ ${ }^{2}$ Royal Flying Doctor Service, North Queensland, Australia \\ ${ }^{3}$ United Nations High Commissioner for Refugees (UNHCR), Geneva
}

\begin{abstract}
In a war context, a transition period begins when the guns fall silent following a ceasefire or a peace agreement is signed. In a natural disaster context, it starts as soon as the search and rescue activities are over. Progression from the emergency to the transition phase is often a tedious process, involving a complex emergency context, unforeseen additional and emerging needs and the presence/withdrawal of stakeholders. Humanitarian aid commonly described in most emergencies often persists during the transition phase. It requires them to make a complete shift in its approach, planning, financing, performance monitoring and evaluation. In transition situations, the key is to develop national and international partnership in respect to primary health centres, with a clearly-defined, realistic and participative public health methodology. This paper, a review of some key humanitarian guidelines and peer reviewed studies, is presented with a methodological approach with a succession of practical questions, answers, and documented case examples and targets central, provincial and district health facilities and national and international public health workers facing the challenges of a fragmented and fragile post-emergency health service network.
\end{abstract}

Keywords: Primary health care, transitional phase, post-conflict, disaster management.

\section{INTRODUCTION}

Over thirty years after the Alma Alta declaration, the WHO conducted a review of the Primary Health Care (PHC) strategy that promised health for all by the year 2000. While our global health context has changed remarkably over the last six decades, the values that lie at the core of the WHO Constitution and those that informed the Alma-Ata Declaration have been tested and remain valid to this day. Despite enormous progress in health care globally, our collective failures to deliver health services in line with these values remain painfully obvious and deserve our greatest attention [1]. This World Health Report revisits the ambitious vision of PHC as a set of values and principles for guiding the development of health systems (universal coverage, service delivery, public health policies, leadership). PHC is no longer the antithesis, as it were, of the hospital, but rather the coordinator of a comprehensive response at all levels of health care delivery.

The pre-requirements needed before applying WHO recommendations are based on stability and political involvement. This report applies when the emergency is over (for war or large-scale natural disaster) and the political stakeholders are slowly returning to function. 'Transition period' or 'phase' is the preferred nomenclature to 'postemergency phase' due to the inherent instability and the possible return to conflict that is characteristic of the post-

*Address correspondence to this author at the Winterberg 17, 1330 Rixensart, Belgium; Tel: +32 474306 144;

E-mail: stephdumortier@hotmail.com conflict environment. Unfortunately $47 \%$ of countries return to conflict within a decade, with a rate that is $60 \%$ in Africa and where the post-conflict infrastructure and system is usually $10 \%$ of what it was before the war [2].

It can be said that emergency medical assistance provided during the early stages of any conflict or disaster, and PHC aimed at promoting and sustaining health in a developing society, are well defined. However, the same cannot be said of the intervening period, namely the transitional period or phase. Such situations require humanitarian actors well versed in the implementation of specific, suitably-adapted work methodologies appropriate to a tenuous transition that uniquely straddles both emergency care and development.

In a war context, the transition period begins when the guns fall silent following a ceasefire or a peace agreement or accord is signed [3]. In a large-scale natural disaster context, it starts as soon as the search and rescue activities are over and no more direct morbidity or mortality occurs related to the disaster itself. It is assumed that the goal is to prevent or mitigate indirect or excess morbidity and mortality that inextricably results from the lack of basic health services, especially if it is not recovered and reconstructed in a timely and accurate fashion. Also, ideally, the affected population will now require less security and a state of improved access to and availability of health services will now exist. Water, food supply and access to quality health care are under recovery and reconstruction. In transition settings, the reasons for substitution-type assistance are no longer justified, and a shift towards support and building upon any local capacity is what is required. 
During human-made emergencies such as war and armed conflicts, or during large-scale natural disasters such as the recent floods in Pakistan or the earthquake in Haiti, the approach of humanitarian actors is to focus initially on protection and search and rescue followed swiftly by developing direct health service delivery system that can independently assume this responsibility itself. Although we might expect local resources to be mobilised and deployed at the earliest stage of a crisis, international health actors often find it necessary to temporarily set up parallel systems or subsume existing fragile health care networks $[4,5]$.

Depending on the context, the rationale for engaging in direct health service delivery in the troubled areas of the country might be justified simply by the chaos, the insecurity, and the overall scale of needs. But the justification may also arise from the emergency and rescue personnel technical skills and background, the specialisations of the humanitarian actors, and the particular mandates of their respective emergency aid donors. Emergency teams often have little knowledge of existing local capacity, and therefore focus on meeting immediate needs rather than focusing on medium- and long-term perspectives.

While the academic humanitarian literature world has drastically expanded in the last decade, most international NGOs actually have their own work methodologies and associated training, but, unfortunately, little about these accomplishments ever find themselves published in the peer reviewed literature where they can be easily found and read. The purpose of this paper is to share with international health workers the best practices and lessons learned from a variety of field experiences devoted to strengthening PHC in transition period situations.

Tragically, the fragmented nature of the humanitarian aid commonly described in most past emergencies often persists during the transition period. It can be exacerbated by competition among health actors to access funds against a pre-defined, easy-to-monitor performance package. As such, it often makes it difficult for national health authorities to rationalise, use, and coordinate the allocated resources properly. The transition period both demands and expects a greater degree of order, planning, and collaborative coordination.

The development of the UN cluster initiative and the health sector wide approach to programming are, among other strategies, welcomed developments that aim to improve health care practice, policy, and coordination in emergency and transition settings. But far removed from the nation's capital or UN Geneva headquarters, the operational reality on the ground often requires humanitarian workers to support, develop and promote quality PHC in close collaboration with national partners, all of who are in transition themselves or remain highly fragile and unstable. In transition situations, the key is to develop national and international partnerships, respectful of PHC, is with a clearly-defined, realistic, participative, and functioning public health oriented health care system. Although it is understood that the recovery of public health infrastructure and protections may return incrementally, leaving the completed transition period behind will only be realized if the public health system and it infrastructure are once again a functioning entity.

Progression from the emergency to the transition phase is often a tedious process, involving unsolved complex emergency problems, additional and unforeseen emerging needs, and the sudden presence/withdrawal of stakeholders. It requires unprecedented international aid to make a complete shift in its approach, planning, financing, performance monitoring, and evaluation.

This document targets central, provincial and district health facilities and national and international public health workers facing the challenges of a fragmented and fragile post-emergency health service network. This approach stresses the need to plan with and build the capacity of national health staff and the system in which they must function.

\section{A COMMON METHOD}

Before deciding to continue in or become involved in a transitional situation, humanitarian agencies need to assess the situation and question their capacity. Post-conflict countries, on an average, are working with $10 \%$ or less of the resources they had before the conflict. There are still levels of conflict that exist despite the claims that the war is over. Weapon availability remains high and many times stakeholders bring weapons into all negotiations, including those that involve health decisions. These levels of violence remain the major reason why so many people flee to urban or other rural conclaves within the country as internally displaced populations (IDPs) or as refugees in a neighbouring country. Reasons for return to warfare can be predicted when economic stagnation and a worsening Infant Mortality Rate (IMR) occur. The IMR is a composite indicator that reflects good governance, access and availability of health care, security, transportation, basic education, etc., so is a most sensitive indicator of a fledgling government's capacity to engage in providing essential services for those in need. Additionally, at the time of any peace treaty or accord, the Emergency Phase indicator of greater than 2.0 deaths $/ 10,000 /$ day day is the most common prevailing indicator. The public health system is not adequate enough to improve this without outside assistance. The populace will be sensitive to the capacity to improve these indices in their decision to remain or flee.

The revision of the NGO's literature and shared experience show a common use of the results-based management cycle: assess and analyse, formulate and plan, implement and monitor, evaluate and learn.

Its common content could be summarised in the following questions $[6,7]$ :

\section{1. "What is Happening Now?"}

The raw data that emerges during a disaster are often imprecise and contradictory, and are rarely an adequate basis for deciding whether action should be taken and, if so, in what form.

- The first requirement is to strengthen regular monitoring during the emergency phase in order to have relevant data to share with stakeholders. This information forms the base for any further involvement of International NGOs in 
transitional situations. This, at a minimum, would include the crude mortality rate which is disaggregated for age and gender and specifically IMR, under age 5 mortality rates (U5MR), and maternal mortality rates (MMR).

- Quick operational surveys are needed to document the results of any humanitarian response to the emergency phase. The methodology used needs to be simple and the results beneficial in terms of services for the population.

- Qualitative data gathered from field experience is essential for the decision-making process.

\section{2. "What is Important?"}

Analysis of these data combined with the experience acquired in the field during the emergency phase will bring into focus a set of problems, some more important than others. The task here is to identify the highest priority problems.

- In dealing with the various partners, actors and authorities, some questions are crucial:

- What is known about the situation today?

- What are the national norms and policies?

- What can be done?

- What will be done by who (shared action plan, transition plan...)?

\section{3. "What Can be Done?"}

Pinpointing the most urgent problems does not mean that they can be solved. At this point, the constraints of the situation help establish priorities for action for each organisation.

- A thorough study is made of strengths and weaknesses, opportunities and threats (a SWOT analysis). Relationships with the authorities are a major factor to consider.

- Choice of target population: displaced persons, childrenunder five, etc. But also type of services (all PHC components, or e.g. Mother \& Child health only).

- The major constraint in involvement in transitional situation is the time component; soft transition is not guaranteed (security issues); there is a need to rebuild some infrastructures; human rights abuses and logistical constraints.

\section{4. "What will be Done?"}

To decide what should be done, planners take note of existing norms and the constraints of the situation. This will allow them to define the limits of what can realistically be attempted - in other words, to set objectives.

- Decisions to take in the light of the political and health situation.

- Mortality and morbidity rates have been ascertained by the assessment, and are our first priority.

\section{5. "How will it be Done?"}

To achieve a particular objective, planners can choose between several types of activity. Initially, they define all the activities that can be undertaken to accomplish a specific objective in a predetermined time frame, and then decide what actions will actually be carried out, and in what order in short, determine a long-term strategy.

- At the decision-making level, it is essential to determine the relationship with authorities and other partners (e.g. having vertical programmes in the same health centre).

- Putting things on a contractual footing through a memorandum of understanding or other documents is an essential approach in agreeing roles, duties and responsibilities.

- Good knowledge of local health economics is important. The cost of care and the patient financial contribution need to be tackled in a spirit of long term and relative sustainability.

\section{6. "What Resources are Needed to do what will be Done?"}

Implementing the chosen activities will require the use of resources (human, material, financial), so resources must be planned for.

- The resources mobilised will depend on the activities planned (see question 5). They may be a limiting factor, such as human resources and their financial support, logistics for medicines, the need to implement a referral system.

- The required timeframe is often medium-term term, from 3 to 5 years. Organisations need to question their financial capacity and their ability to hire and maintain skilled and experienced staff.

- While it exists, there is a possibility of a shared approach via the cluster system.

\section{7. "How will Activities be Implemented?}

- This is the action stage - the stage when the decisions made are implemented and the activities carried out, with maximum involvement of the local authorities. This is the place for quality improvement across the different services.

\section{How do you Determine what was Accomplished?}

The evaluation of what has been achieved should cover not only the resources used, but the entire planning process (quality of services provided, impact on the victims' health, and so on). This is known as monitoring and evaluation.

- A substantial number of indicators have been provided in this document in relation to the possible objectives chosen. Documenting impact is more difficult, but should be a priority in transitional situations.

- Planning the documentation of the results of activities undertaken should be done at the early stage, especially in the transitional phase.

\section{THE PRIORITY TO ADDRESS PRIMARY HEALTH CARE SERVICES}

According to the Alma-Ata conference, $\mathrm{PHC}$ is the first level of contact of individuals, the family and the community with the national health system, bringing health care as close as possible to where people live and work $[1,6]$. The declaration also attaches great importance to community participation at a cost that the community and the country can afford to maintain at every stage of their development. 
Since 1978, many countries have incorporated the concept of PHC into their national health system. PHC services are often grouped in packages. Current packages vary from country to country: the listings can be long and at times confusing. Some packages focus on a specific target populations for example; (infants under 1 year, children under 5 years, women, pregnant and lactating women, and the elderly), while others target specific types of care, such as mental health and dental health.

Fig. (1) illustrates some of the existing packages in relation to essential services: preventive, screening \& testing, curative, follow up \& referral services. The bottom part of the figure illustrates the support system essential for all services. In conflict areas, this representation of PHC could seem an impossible ideal to reach. Accordingly, some NGOs focus on bolstering one or two services in order to recover and maintain basic/essential health care. Doing this provides the greatest opportunity to control post-crisis mortality and morbidity.

Assessment is the process and activities involved in gaining an understanding of a situation in order to identify problems (e.g., their capacity, components and stakeholders).

Every PHC manager should obtain and be able to answer the following questions of different service levels at National, Regional/Provincial, and District Health centres [810]. This information will be reported in the project document.

To be able to perceive/grasp/understand the PHC system and health policy of the country, the possible sources of information are the Minister of Health and the programme directors. This will focus on the following;

- National health policies including PHC and Hospital policy and norms

- National and district strategic plans and budgets

- Main stakeholder mapping

- National protocols and guidelines in use

- National Essential Drugs list and their level of use

- National Pharmaceutical policies (quality assessment, importation, registration,...)

- Availability of medical school, health staff and training

- Human resources national policy (job profiles, salary policy ...)

- Cost sharing policy and "most vulnerable" criteria, prepayment systems

- National referral system

- PHC packages, existing programmes (Vaccination, HIV, Reproductive health, Behavioural Change Communication, etc.)

- Environmental health policy (waste management, etc)

- Community organisation (guidelines, rules and regulations)
$>$ Health Committee
$>$ Community Health Workers
$>$ Traditional Birth Attendants

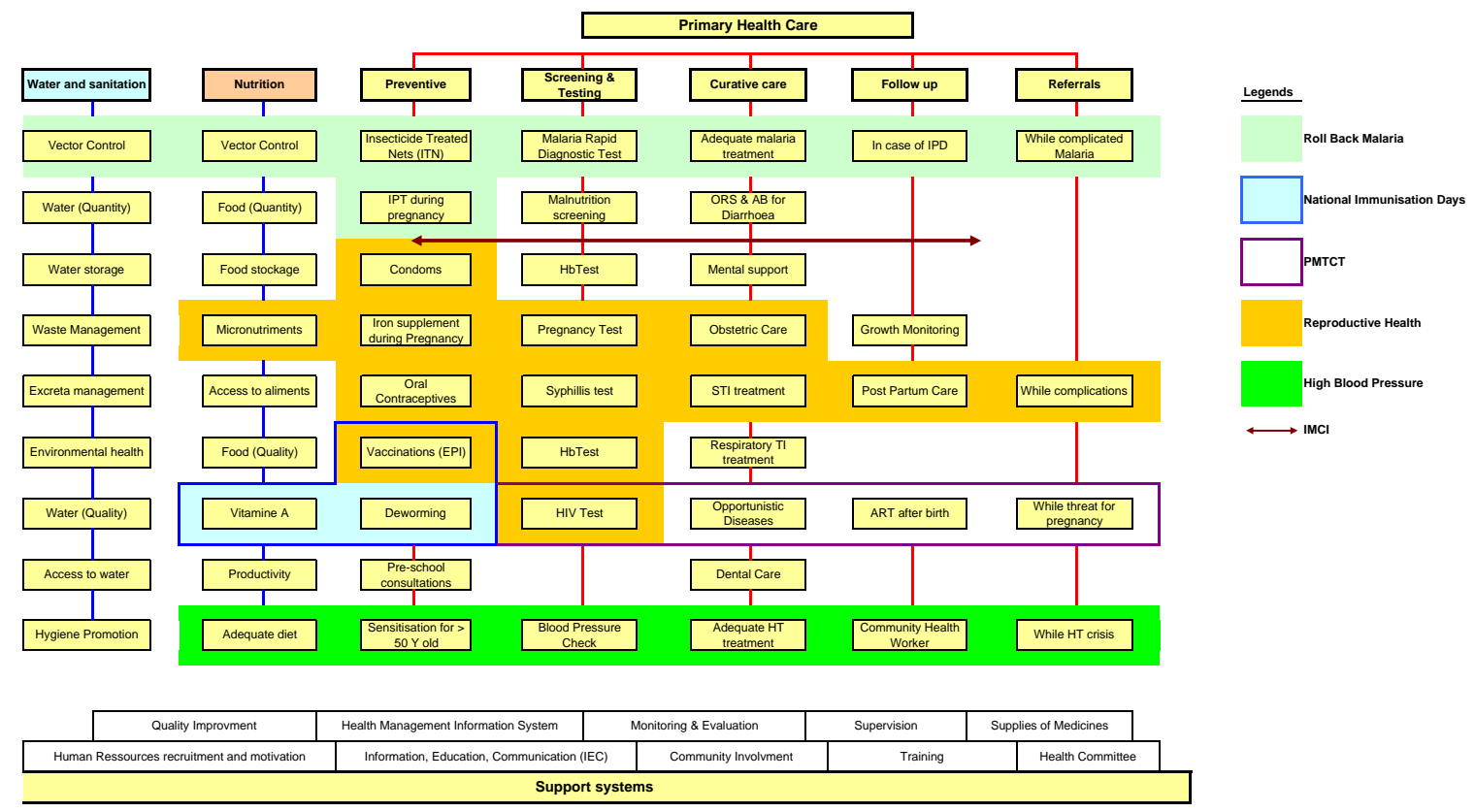

Fig. (1). The constituents of Primary Health care and examples of existing programmes. 
To know the profile or demographic data of the population concerned, and to achieve a mapping of all these components, demographic health surveys, census data, existing population-based surveys and interviews are needed.

- Health Centre catchment areas and population with demographic profiles that are disaggregated for age group, gender, etc.

- Dynamics, magnitude of the population in affected areas (Nomads, Displaced persons, community involvement in health care).

- Recognition of groups and areas most at risk and

- their accessibility to all levels of health system; geographical, financial, cultural, equity;

- their protection related issues (violence and security);

- their access to water and sanitation;

- their loss of production, food stock, purchasing power and commerce; and

- their coping mechanisms.

- Health seeking behaviour.

- Population perception of the NGOs.

The main health problems of the population are usually found in the Health Information System, Early warning systems, specific data related to specific threats (Ebola, HIV, etc), National Surveys, and NGO survey/data/information [11]. Their completeness and accuracy should be questioned.

- Morbidity and mortality rates

- by population: neonatal, infant, less than 5 , pregnant mothers, stratified by age and gender;...

- for the main prevalent diseases/health problems and their sequences over time period; and

- linked to recent outbreaks, seasonal epidemic (meningitis...)

- Vaccination status

- Nutritional status

To evaluate the existing capacity in the health sector (including but not limited to effective involvement of $\mathrm{MoH} /$ partners/NGOs), the PHC managers seek assistance of the local press and/or do focused interviews to be able to validate and describe:

- Number of staff, level of qualification, regularity of salary,

- Security problems

- Type of supervision, frequency and monitoring tools, Information Education Communication material

- Community link and community participation

- Referral (in and out) system to higher level of care (tools in place)

- Identified and perceived service gaps/ "marginalised to health care" population, armed opposition...)

- Continuity and sustainability of supply system

- Local budget if any

- Interventions of the various stakeholders
- their mission, activities and problems encountered

- the mapping of their presence, timetable and logistic network

- the security issues

\section{THE DECISION OF INTERVENTION}

In an emergency situation, the decision for intervention in the transitional period will not be a smooth process for most of the participating NGOs. To avoid a wrong decision, NGO decision makers will first consider certain criteria and then assess further elements before initiating technical support to a health infrastructure. These criteria are:

- A public health analysis to ascertain population needs.

- The opportunity to improve access for beneficiaries.

- A documented knowledge of the security situation: PHC programmes are not drop-off programmes; they require regular access to the $\mathrm{HC}$.

- Logistic feasibility: distances, accessibility, means of transport, time required to reach the PHC.

- Acceptability: Are the local population, community and authorities aware of and informed about the role and objectives of humanitarian workers?

- Comprehensive health actors mapping. Avoiding duplication: Is another organisation already supporting the PHC?

- Assurance that the facilities to be supported are recognised by the $\mathrm{MoH}$ as part of the public health network and that the procedures for setting up PHC services are consistent with national health policy.

When the decision to intervene is taken, some common prerequisites must be considered in respect of project and budget planning:

PHC support is not a short-term action. Experience suggests that a commitment of 3 years is reasonable, and private fund donors must be secured to guarantee finance for this period before starting the programme.

The health infrastructure should be operational and provide a safe working place with minimum bio-safety guaranteed. Rehabilitation/extension of the existing clinical buildings, staff quarters, latrines, bathing area, water source and waste management system may be required.

Donations of medical equipment, furniture, initial (or continual) supply of medicines and commodities such as stationary and cleaning agents will also be a consideration.

Human resources will be appointed according to needs, existing PHC resources and the catchment population (taking into account a possible increase in population due to displacement). PHC activities and the size and diversity of services available have to be taken into account. (See Chapter 3, administrative files).

Setting health objectives and priorities in the transition period follows a balanced analysis of the region's most prevalent diseases (the incidence of which can be increased by population displacement, in turn, leading to possible outbreaks) and the population's perception of what the health issues are. In addition, the threat of sexual violence increases among populations forced to live in very closely confined quarters. 


\section{Box 1. Human Resources Needs for PHC Services}

As early as the 90 s, some rules of thumb for Human Resources needs
were proposed by various NGOs and reproduced in the SPHERE
document: for curative care, a minimum of 1 qualified health employee
based on 1 person for 50 consultations per day, plus 2 to 5 workers
(locally trained person for ORT, dressing, registering, and so on)
According to our priorities illustrated in Fig. (2), we can identify the
human resources required to deliver selected activities and which
activities to concentrate on, depending on the constraints of available
health personnel.
The catchment population (see Box 2 ) and its demographic proportions
(pregnant women, infants under 1 year, children under 5 years) are used
to identify the anticipated PHC workload (excluding accessibility and
protection issues).
In preventive care, the services involved are the vaccination programme,
ANC, deliveries, Mother \& Child Health. It can also include the follow-
up of hypertension, diabetes and other chronic diseases in other contexts.

The aim of any intervention (desired impact) is to contribute to the reduction of mortality and morbidity and to alleviate suffering due to conflict conditions.

In most situations, the pre-crisis situation is the theoretical minimum standard to be reached. In others, in the event of an absence of standards or protracted active conflict, internationally recognised standards will have to be the reference. Pre-crisis baseline information may be scarce or incomplete. If none is available, then surveys to capture the information will have to be carried out at the time of inception. Such operational surveys identify general health problems and their scale, as well as their main components.

The planning process converts the problems that have been identified into objectives, and is based on a collaborative and long-established but simple logical framework approach.

A general objective (GO) is then set to address a defined health problem facing the population. It will be a clear statement of the result to be achieved by our intervention in the following 1 to 5 years.

The next step is the choice of corresponding specific objectives (SOs) at PHC level. The SOs are service-based and include planned quarterly reviews of the activities required.

The level of PHC staff and Health Committee engagement in the choice of SOs and activities varies considerably from one context to another. In the Democratic Republic of Congo, all clinical assistants and nurses are trained in the SO concept, while in Uganda only the best clinical assistants received public health training. In some very remote areas, the SOs was not shared due to a lower level of public health education.

In respect of the objectives set for the 2 to 3 year project, the preference is to use quarterly planning rather than an annual framework since the dynamics of the context change as it develops.

Table $\mathbf{1}$ is an example of some possible GOs, and their corresponding SOs and possible indicators.

The target values of indicators will vary from one country/situation to another. The performance tables described later in the document will contain a space for the values to be attained in compliance with international/ national norms.

After agreeing the SOs, the PHC manager has to specify the activities with maximum of $\mathrm{HC}$ staff and community involvement.

To specify these activities, the PHC manager must decide what services will be provided within PHC. There may be a curative service, a preventive service, such as immunisation, or a maternal and child health care service. These services must address the main pathologies encountered.

After this decision, the manager determines what activities shall be restored, reinforced, or supported first [12, 13]. The choice of activities must be based on health priorities. However, such priorities will depend largely upon:

- Implementation opportunities: for example human resources, both local and expatriate, logistical resources, and the time that can be spent on the spot in the light of the security situation.

- And the population's own perception of the situation should never be overlooked.

\section{Box 2. The importance of the denominator}

While population count methodologies are well described for complex emergency situations and camps, the search for a denominator in transitional situations, when citizens have started to go back home, is less systematic.

Desk review (of existing documents), estimation (after interviews/focus groups), survey, registration and census are the 5 methodologies described where NGOs avoid substituting services for those already provided by local authorities. De facto, census or even survey data are always extremely political in conflict areas.

Some of the tools proposed in this document, such as the Results Illustration Chart (RIC), are useful only when a denominator, even if imprecise, is known: a trend can then be identified and later fine-tuned when a more relevant denominator is identified.

While Fig. (3) illustrates a complete and ideal PHC service, prioritisation is essential to respond to the more essential needs. Examples of the prioritisation process for a given situation include:

- In the case of vaccinations: when there is an epidemic outbreak, social mobilisation will take place spontaneously as soon as information about the time and place of the vaccination campaign begins to circulate. When there is no epidemic, mobilisation may take much more time and require more resources.

- The incidence of Malaria is seasonal. While good diagnosis and treatment are always a priority, the distribution of Insecticide Treated Nets is a dedicated activity during the last days of the dry season.

- Ensuring immunisation during Antenatal Care will always be a first priority, preceding the prevention of mother to child transmission where more training is needed to handle a more complex process.

- While people in distress will benefit from community based support, common mental disorders will be treated at the health centre and severe mental disorder referred to specialised psychiatric services 
Table 1. From the General Objectives to their Corresponding Indicators

\begin{tabular}{|c|c|c|}
\hline General Objectives & Specific Objectives & Example of Indicator \\
\hline \multirow{10}{*}{$\begin{array}{l}\text { Patients have access to well } \\
\text { functioning and equipped } \mathrm{HC} \text {, with } \\
\text { sufficient staff to provide quality } \\
\text { PHC services. }\end{array}$} & \multirow{3}{*}{$\begin{array}{l}\text { Community Health Workers and Traditional } \\
\text { Birth Attendants are fully operational in the HC } \\
\text { catchment area.The sustainability of their referral } \\
\text { activities is supported through capacity } \\
\text { building,monitoring and evaluation }\end{array}$} & Attendance rates (Total population and under 5) \\
\hline & & Sum of all new cases at the $\mathrm{HC}$ \\
\hline & & No of referral to $\mathrm{HC}$ for deliveries \\
\hline & \multirow{2}{*}{$\begin{array}{l}\text { All Human Resources required are } \\
\text { appointed,working and supervised regularly }\end{array}$} & $\begin{array}{l}\text { Nr of human ressources posted / present comparing to national norms } \\
\text { or needs }\end{array}$ \\
\hline & & $\mathrm{Nr}$ of consultations per clinician per day \\
\hline & \multirow{2}{*}{$\begin{array}{l}\text { Adequate buildings, furniture \& equipment are } \\
\text { guaranteed according to national standards (if } \\
\text { existing) }\end{array}$} & Availability of water, latrines and waste management system. \\
\hline & & Availablility of communication and transport means for referrals \\
\hline & \multirow{3}{*}{ Quality drug management system is guaranteed } & $\begin{array}{l}\text { Nr of days of rupture of stock for the treatment corresponding to the } 4 \\
\text { more prevalent diseases. }\end{array}$ \\
\hline & & Absence of expired drugs at $\mathrm{HC}$ \\
\hline & & Presence of a functional rehydration corner \\
\hline \multirow{6}{*}{$\begin{array}{l}\text { Population of the catchment area is } \\
\text { protected against epidemics and } \\
\text { major communicable diseases }\end{array}$} & \multirow{2}{*}{ Outbreaks are prevented and recognised } & Outbreak investigation, control plan and protocols in place. \\
\hline & & Availability of quality laboratory tests \\
\hline & \multirow{2}{*}{$\begin{array}{l}\text { Communicable diseases are properly managed } \\
\text { (Malaria, HIV/AIDS, Tuberculosis, Cholera, } \\
\text { Meningitis...) }\end{array}$} & Nets coverage and retention rate \\
\hline & & Specific mortality rate \\
\hline & \multirow{2}{*}{$\begin{array}{l}\text { Health Information System and analysis at HC } \\
\text { level (Results Illustration Charts)are conducted } \\
\text { monthly }\end{array}$} & Crude mortality rate, under 5 mortality rate. \\
\hline & & $\begin{array}{l}\text { Health information data are completed accurately every month and } \\
\text { available at the HC }\end{array}$ \\
\hline \multirow{5}{*}{$\begin{array}{l}\text { Patients benefit from quality } \\
\text { curative cares. }\end{array}$} & \multirow{3}{*}{ Clinical case management is improved } & Knowledge and practice of national protocols \\
\hline & & Rational Prescription Indicators (WHO) See Ref. \\
\hline & & $\begin{array}{l}\text { Incidence rate for most common diseases and for the most prevalent } \\
\text { chronic disease }\end{array}$ \\
\hline & \multirow{2}{*}{$\begin{array}{l}\text { Rules of Universal Medical Precautions are } \\
\text { respected }\end{array}$} & Availability of equipment and its correct use \\
\hline & & Blood transfusion safety indicators to apply if presence of blood bank. \\
\hline \multirow{8}{*}{$\begin{array}{l}\text { All women benefit from quality } \\
\text { family planning, antenatal and } \\
\text { postnatal care, safe delivery and } \\
\text { comprehensive care in case of } \\
\text { violence. }\end{array}$} & \multirow{2}{*}{$\begin{array}{l}\text { Antenatal clinics are held in compliance with } \\
\text { national norms. }\end{array}$} & $\begin{array}{l}\text { Percentage of pregnant women attending ANC 1,2,3,4, during last } \\
\text { trimester }\end{array}$ \\
\hline & & $\begin{array}{l}\text { Percentage of woman who received malaria preventive treatment } \\
\text { twice during pregnancy in respect of national protocols. }\end{array}$ \\
\hline & \multirow{2}{*}{ Deliveries are made to health center } & Percentage of pregnant women delivering in the $\mathrm{HC}$ \\
\hline & & Number of births / deaths / complications. \\
\hline & $\begin{array}{l}\text { Family planning consultations are regularly } \\
\text { delivered }\end{array}$ & Percentage of women accessing Family Planning consultations \\
\hline & \multirow{3}{*}{$\begin{array}{l}\text { Comprehensive treatment is given to women } \\
\text { victims of violence }\end{array}$} & Correct use of protocols \\
\hline & & Use of private consulting room \\
\hline & & Availability of emergency contraception. \\
\hline \multirow{5}{*}{$\begin{array}{l}\text { New born \& Children benefit from } \\
\text { quality preventive and curative care }\end{array}$} & \multirow{3}{*}{ A functionning vaccination service is in place } & Quality of cold chain is monitored and there is no break down. \\
\hline & & $\begin{array}{l}\text { Percentage of children less than } 1 \text { year old who received DPT } 1,3 \text { and } \\
\text { Measles vaccinations }\end{array}$ \\
\hline & & Drop out rate \\
\hline & \multirow{2}{*}{ Growth monitoring consultation are delivered } & Nr of low weight for age \\
\hline & & $\mathrm{Nr}$ of cases of malnutrition identified. \\
\hline \multirow{3}{*}{$\begin{array}{l}\text { Patients have access to well } \\
\text { functioning secondary health } \\
\text { facilities and are able to reach them } \\
\text { on time to receive correct services }\end{array}$} & $\begin{array}{l}\text { Identification of the patients requiring further } \\
\text { services is functional }\end{array}$ & Nr of patients / pregnant women / victims of rape referred. \\
\hline & A referral system is in place and functioning & Availability of transport means \\
\hline & $\begin{array}{l}\text { The secundary health facility provides quality } \\
\text { care }\end{array}$ & $\mathrm{Nr}$ of patients referred who reached the hospital \\
\hline \multirow{3}{*}{$\begin{array}{l}\text { The community plays a substantial } \\
\text { role in the PHC services }\end{array}$} & $\begin{array}{l}\text { There is a functionning Health Committee in } \\
\text { compliance with national norms (Finance, } \\
\text { medicines, cost sharing...) }\end{array}$ & See national norms \\
\hline & \multirow{2}{*}{$\begin{array}{l}\text { The community is aware of the main health } \\
\text { threats or diseases }\end{array}$} & Nets retention rate \\
\hline & & Knowledge Attitude Practice surveys \\
\hline
\end{tabular}


Table 2. Reproductive Health and Priority Actions

\begin{tabular}{|c|c|c|}
\hline & Crisis: Minimum Reproductive Health Services & Transitional Situation: Comprehensive Reproductive Health services \\
\hline Family Planning & $\begin{array}{l}\text { Provide contraceptives, such as condoms, pills, } \\
\text { injectables and IUDs to meet demands }\end{array}$ & $\begin{array}{l}\text { - Source and procure contraceptive supplies } \\
\text { - Provide staff training } \\
\text { - Establish comprehensive family programs } \\
\text { - Provide community education }\end{array}$ \\
\hline $\begin{array}{l}\text { Gender- Based } \\
\text { Violence }\end{array}$ & $\begin{array}{l}\text { - Provide clinical care for survivors of rape } \\
\text { - Coordinate mechanism to prevent sexual violence } \\
\text { with cluster members } \\
\text { - Inform community about services }\end{array}$ & $\begin{array}{l}\text { - Expand medical, psychological, social and legal care for survivors } \\
\text { - Prevent and address other forms of gender based violence. } \\
\text { - Provide community education } \\
\text { - Engage men in boys in gender based programming }\end{array}$ \\
\hline $\begin{array}{l}\text { Maternal and } \\
\text { newborn care }\end{array}$ & $\begin{array}{l}\text { - Ensure the availability of emergency obstetric and } \\
\text { new born care services } \\
\text { - Establish } 24 / 7 \text { referral system for obstetric and } \\
\text { newborn emergencies } \\
\text { - Provide clean delivery packages to visibility } \\
\text { pregnant mother and birth attendants } \\
\text { - Inform community about services }\end{array}$ & $\begin{array}{l}\text { - Provide antenatal care } \\
\text { - Provide postnatal care } \\
\text { - Train skilled attendants ( midwifes, nurses, doctors) in performing } \\
\text { emergency obstetric and new born care services } \\
\text { - Increase access to basic and comprehensive emergency obstetric and } \\
\text { new born care services }\end{array}$ \\
\hline $\begin{array}{l}\text { STIs, including } \\
\text { HIV, Prevention } \\
\text { and Treatments }\end{array}$ & 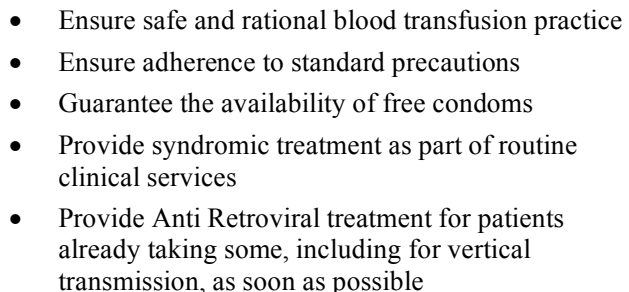 & $\begin{array}{l}\text { Establish comprehensive STI prevention and treatment services, } \\
\text { including STI surveillance systems } \\
\text { - Collaborate in establishing comprehensive HIV services as } \\
\text { appropriate } \\
\text { - Provide care, support and treatment, for people living with } \\
\text { HIV/AIDS } \\
\text { - Raise awareness of prevention, care, treatment services of STIs }\end{array}$ \\
\hline
\end{tabular}

- Information, education, communication sessions are a priority in outbreaks such as cholera or Ebola. In other situations, the time spent on these sessions has to be balanced alongside other priorities.

Table 2 illustrates the top reproductive health priorities in two different health situations.

Once a decision has been made about priority actions, the PHC manager decides who is willing and able to do what tasks.

This entails reconsidering the various modes of action.

Some examples include:

- If no health staff is available on the ground for this specific service: mode of action = substitution . Example: No midwife for deliveries or ANC

- With what health care providers are available is task shifting an option?

- If health staff is available on the ground, the NGO has to train them so that they can conduct health education sessions: mode of action = support.

- If there is a local organisation with potential capacity: mode of action $=$ mobilisation .

- If more human resources can be assigned to the health centre: mode of action $=$ persuasion .

Each activity is regularly reviewed in the light of the corresponding mode of action, bearing in mind that preference must be given to the mode of action that involves the least substitution possible.

There is possible synergy between different NGOs but also risk of antagonism. While some organisations have a general all-component PHC approach, some others are focusing on vertical programs like ante natal care, HIV, or vaccination programmes. Different modes of action in one district could create a cacophony (see Box 5). Coordination between partners is essential.

Box 3. Sudan Darfur 2005-2006: Selecting the Services to Support

Hundreds of organisations are present in Darfur where programmes are difficult to implement due to security problems.

The ICRC has different modes of action for medical programmes. The PHC clinic at Gereida or the Field Surgical Team is on substitution mode. The ICRC does everything from $\mathrm{A}$ to $\mathrm{Z}$ and has its own personnel. In other regions of Darfur, the ICRC has chosen to support existing health centres through the Ministry of Health.

As described in this methodology, the main priorities were set by PHC staff and community representatives. The clinical services are delivered by $\mathrm{MoH}$ clinical staff with the ICRC supplying medications. Antenatal consultations (ANC) were run by the ICRC's midwives working with local TBAs.

Sadly, very few indicators were shared with the community (lack of security, education level)

\section{Continuity of Care: Referral to Hospital}

The PHC managers should not underestimate the humanitarian, political (especially in post-conflict areas), and 
economic importance of referral health care $[15,1]$. PHC policy will neither be understood nor accepted by beneficiaries without a proper system to optimize availability and access care for more complex cases.

If medical conditions cannot be managed at the PHC facility level, referrals for emergency or essential medical, obstetric and surgical care is required to the nearest appropriate care facility. While life-saving emergency care is rarely subject to discussion, the definition of what type of cases should be referred is commonly a source of debate and misunderstanding. Standards Operating Procedures or guidelines are needed to define basic principles, taking into account shortfall in health systems, and to clarify common misunderstandings:

Establishing and managing a referral scheme presents many challenges:

- The PHC approach is part of most MoH health strategy. Depending upon the context, funds and logistics, secondary and tertiary care may not be given the same emphasis. The budgets allocated to public sector treatment for costly and long-term diseases, such as cancers, are difficult, and prioritisation will be necessary.

- Inequity in access to second level of care can create tensions, particularly during fragile transition periods. For example, it is important to secure provision of similar services for refugees, displaced persons or the local population. In post-conflict situations, similar access to referral care must be granted to all, irrespective of ethnic, social, political or gender considerations.

- Urban populations have the tendency to shop for care, regardless of official regulations on patient channels. There is a wealth of attractive, urban private sector facilities available. Primary level care might be bypassed.

- Any referral system takes into account local demographics and the incidence of diseases as well as the level of development of the host country's health system. This includes issues related to co-payment and specifics related to various standardised treatment procedures. The availability and capacity of the host country's existing referral facilities are crucial.

The UNHCR defined guiding principles that are useful for the management of any medical referral system [15]

- Impose Primary Health Care as the first level of care,

- Define clearly what pathologies or investigations are eligible for referral,

- Avoid use of parallel systems and build on existing structures,

- Secure and monitor equality of care and access among PHC programme catchment population,

- Ensure that emergency referral is based on prognosis by a health professional,

- Organise a transparent, documented decision-making process based on cost and prognosis when it comes to elective and semi-elective referral.
- Secure the transparency of the process through consultation and strong communication and dissemination with all stakeholders,

- Limit the number of agreed upon referral facilities with appropriate contractual relationship,

- Coordinate with and support main referred diseases prevention programmes.

It is crucial to ensure that patients are aware of the potential limitations of referral care. Procedures need to be defined with health authorities, and shared and agreed upon with all relevant stakeholders, including the aspect of food and transport.

With respect to transport, an NGO will have different options, ranging from supporting a local taxi or ambulance system to the use of their own logistics. An NGO may have an agreement with the referral hospital, for example in terms of medical donations, coverage of patient's fees, payment for food and accommodation, and financial assistance. There are specific situations whereby NGOs may be able to support patients' access to further specialist treatment, such as repair of vesico-vaginal fistulas, orthopaedic services, paediatric surgery (see Box 4; Uganda).

\section{Box 4. Uganda 2008: Continuity of Care}

Some HCs in Northern Uganda can be up to $80 \mathrm{~km}$ from the respective referral hospital. Various NGOs provided bicycle-ambulances to the main villages in the respective catchment areas. This facilitated early stage referral to the $\mathrm{HC}$.

The onward link from the $\mathrm{HC}$ to the referral hospital was more uncertain. The few, strategically located district ambulances were rarely operational. Faced with a life-threatening emergency, NGO personnel had the following options:

- mobilising the patient's relatives to provide their own means of transport

- $\quad$ supporting HC staff in their request for the district ambulance

- mobilising community participation to pay ambulance fees of 30 USD

- driving the patient ourselves when all other options failed

In Pader district, some NGOs, such as MSF, paid for the treatment of referred patients, while ICRC preferred a fixed quarterly cash payment to the privately run referral hospital at Kalongo.

\section{Agreements, Roles and Responsibilities}

While legal and administrative agreements might not be perceived as a priority during the acute phase of a crisis, it is important to set up and clarify roles and responsibilities as soon as possible when supporting Primary Health Care within existing $\mathrm{MoH}$ Health structures.

The MoU is a contract, which formalises the relationship with the relevant authorities such as Ministry of Health $(\mathrm{MoH})$ when available and the NGO. When possible, it is completed with the $\mathrm{MoH}$ at regional or district level where there are supported health centres.

This contract spells out respective roles, responsibilities, commitments and timeframes. (Technical specifics such as allowances or per-diem allowances should be included in an annex, which can be easily reviewed). 
The MoU serves as a form of governance of the partnership, and provides a useful reference document to ensure continuity in the event of staff changes. Such a partnership requires transparency, trust, cooperation and compromise on both sides. Empowering the $\mathrm{MoH}$ (upgrading training, enhancing responsibilities) improves the quality of activities and helps facilitate the handover.

An MoU is a legally binding document that has been checked by a legal adviser and prior to signing, for compliance with regulations. Oversights may prove costly; for example, failure to specify that the $\mathrm{MoU}$ will be cancelled if the NGO has to pull out of the region or country.

The majority of civil servants are underpaid. Motivating health staff is a crucial issue, and must be achieved without creating a culture of dependency on external aid and/or discrepancy among sectors. A national salary can be improved by a "per diem" (a daily monetary allowance) when staff members are involved in field trips or training activities. This per diem allowance can be paid by the $\mathrm{MoH}$ or by partners. In most countries, there are official rates for per diem allowances that have to be taken into account when supporting $\mathrm{MoH}$ staff during activities (coordinate with different international NGOs).

Like all matters related to money, the subject is sensitive and requires multi-sector collaboration (education, agriculture, civil engineering, police, etc).

$\mathrm{MoH}$ salaries for PHC workers to improve performance might be an approach, but there is no literature documenting such a performance-related pay approach as being successful in terms of quality improvement. In most situations, it transformed the NGO into a second authority while the quality-linked top-up was taken as a salary, generating tensions/strikes in the event of the NGO's refusal to pay.

At HC level, rewards can be used. HC staff, together with the NGO team, can determine strict criteria to be met within an allocated period of time (3 to 6 months). These criteria could include stock management issues, compliance with hygiene protocols, infection control, HMIS completion, and also the percentage of immunisation and deliveries within a determined period. Rewards could be in cash or kind, in agreement with the authorities. In Uganda, ICRC signed 6 month agreements with each $\mathrm{HC}$, these agreements being counter-signed by District managers. 9 of the $14 \mathrm{HCs}$ achieved their targets and received food rewards. Rewards agreements were adapted and put in place every 6 months.

To motivate target populations, it is worth considering the introduction of incentives. Positive experiences with direct results are, for example:

- Basic food packages are offered in the Iraqi immunisation system

- 'Mama kits' are given during delivery at the level of the maternity unit (clean razor blade disinfectants, Tetracycline eye ointment, gloves, ligature, soap, sanitary pads, towel, etc)

- Insecticide treated nets are given during the second antenatal care visit the mothers, but also to their partners if they accompany them.
- Sanitary pads are given to women in post partum consultations

- Fabric is given to any couple attending family planning sessions regularly for 9 months

- Cash transfers were available in Latin America upon completion of an immunisation schedule.

\section{Exit Strategy}

The label 'exit strategy' itself hints that the concept of sustainability remains a fallacy in social services provision. Health is not a for-profit service. Somebody will have to pay for it. It is not about self- sustainability but about identifying who will pay for it. However, there is an obligation to prepare a smooth phasing out of support as the situation stabilises and funding comes to an end. Coordination meetings are the first place to inform and debate the limits of the MoU and the challenges to stimulate NGO involvement.

Most NGOs involved in transition situations start their programmes in the emergency phase (conflict or natural disaster) and the exit strategy is overlooked.

In the support mode, the principal actor likely to take over is the MoH. Under the terms of national health policy, agreement will be reached centrally or at district level.

Exit strategies are flexible and based on objective criteria which could be categorised as technical, managerial, and financial accountability, for example:

- availability of human resources, their skills and their salaries,

- regular provision of medical supplies and the capacity to manage them,

- regular supervision,

- reintroduction of cost sharing in respect of national norms and policies. In order to share a clear message that prevails despite inevitable staff changes,

- the plan of action includes a written agreement whereby partners pledge to take over the programme according to a set timetable and a plan for monitoring the programme

Regular supervision/monitoring should start as soon as possible. Whenever the district staff is available, trainings/updates should be facilitated by the $\mathrm{MoH}$ with the support of the NGO. Thus the exit strategy becomes a smooth and progressive procedure.

In practical terms, the situations where an exit strategy proved successful were those in which a development partner, such as the World Bank or USAID in Afghanistan, took over the health sector component. Sustainability is otherwise unlikely.

\section{THE INTERVENTION}

All participating NGOs share two similar principles for PHC support during crisis situations: the first one being the proximity to the beneficiary, the second one the expectation to raise the level of care to the one available before the crisis (or better, meeting international standards if absent before conflict). Special attention is given to existing PHC packages in place pre-crisis and their documentation (Baseline data, key informants). 
These principles are enshrined in the participatory approach that is recommended at the earliest stage of assistance to any crisis-affected population (see Fig. 2).

Despite well-known international standards [23, 24,] as WHO, UNICEF, Sphere, and ALNAP, PHC quality performance may fall below these standards in transition situations in developing countries. As illustrated in Box 6, quality improvement opportunities are possible only when PHC staff and the population are involved [25].

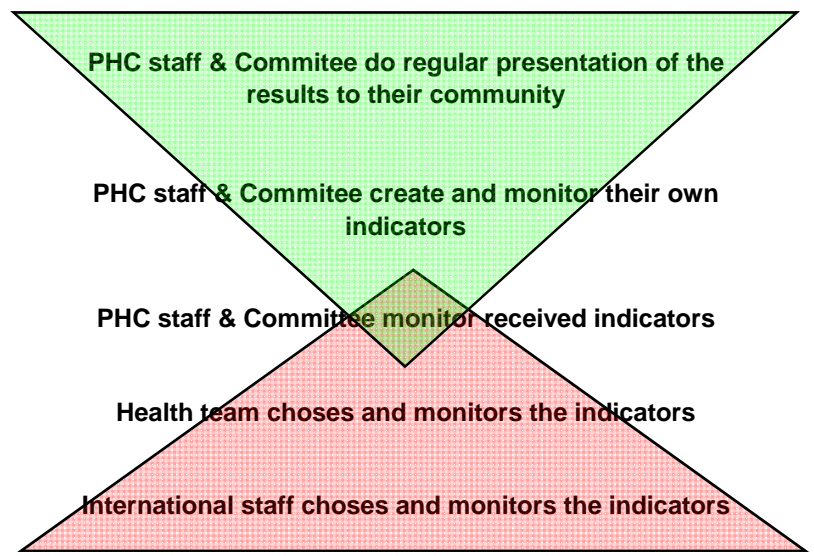

Fig. (2). Different levels of participation of the crisis-affected population to the PHC program.The green pyramid shows community involvement but also quality improvement opportunities. The red pyramid represents decreasing NGO support as the community takes over.

All aspects of health care are subject to quality improvement; PHC staff may not be motivated to work properly, resources may be misused and patients will be prompted to access poor quality services only as a last resort. A PHC programme offers the opportunity to improve both the quality of services and activities.

As represented in Fig. (3), medical care goes beyond strictly clinical activities. Support systems are essential, such as a safe \& hygienic environment, monitoring, empathy, respect for patients and caregivers, and Information Education \& Communication sessions.

A systematic, permanent process to assure and maintain quality is needed for an efficient health system.

The different aspects of quality of care are: competence, performance, effectiveness, efficiency of care, security, accessibility, interpersonal relationships, continuity and utilisation of services.

Quality assurance methods are based on 4 priorities [26]:

- client needs. The external clients are the patients and the community, while the internal clients are the HC staff.

- systems and processes. Work is the result of a succession of steps or activities. The PHC manager analyses these different steps to know what to change and improve.

- data-based decisions. Having a hunch is the first step, having proper data is the next. Working with indicators and data gives us the opportunity to document our quality improvement.
- team work. The people involved in the daily delivery of health services know better than anyone else the problems that they face. Proposals from PHC staff have more chance of being implemented than those from outsiders.

The following elements of quality improvement must be considered [27]:

- The scope of practice of the PHC: What conditions will be treated/ referred and by whom?; limits of these activities; appropriate triage

- National validated protocols: How are they applied? Does the $\mathrm{MoH}$ need our input to adapt/ renew them? Are local guidelines available?

- National essential drug list and customs regulations; level of medicine according to level of care (Health post, health centre, referral health centre...)

- Adequate quantity and quality of staff. Training in line with clinical, management legal capacity?

- Respect for and sensitivity towards patients and colleagues. Privacy? Patient confidentiality? Ethics and accountability?

- Good documentation and use of the Health Management Information System

- Adherence to infection control measures such as standard precautions, essential requirements and basic hygiene, importance of following established laboratory protocols.

\section{Box 5. The Difficult Question of Cost Sharing in Transitional Situations}

The appropriateness of user fees for services used by the poor has become an important point of debate [16-18], particularly in the light of commitments made to achieve international development targets.

Emergency humanitarian health organisations are reluctant to apply cost sharing schemes to the population they serve. If protection and access to health services, free of charge, is part of the basic package for any victim during the acute phase of the humanitarian crisis, it may become controversial during the transition phase.

When applied in parallel with cost sharing, free services often represent unfair competition with the national health system. It hampers $\mathrm{MoH}$ policy and operation. The same emergency organisations find themselves confronted by national health policy on the reintroduction of user fees and also local health insurances.

Studies in Africa [19] show a reduction in the use of health services when user fees are introduced. The result is that a significant increase in available funds has been achieved in only a few isolated cases (e.g., southern Mali, Cameroon). There is scant proof of any link between the introduction of user fees, and the inevitable ensuing reduction in the number of consultations, and an improved quality of services. Improved quality of care may well increase the use of health services, but user fees can severely limit poor people's access to health care.

In Uganda, the elimination of user fees has boosted attendance at health centres, but the long-term negative effects anticipated by Burnham et al in their article are proved by $\mathrm{Xu}$ et al in their impact analysis a few years later to be much worse than expected $[20,21]$ :

"Unexpectedly, the incidence of catastrophic health expenditure among the poor did not fall. The most likely explanation is that frequent unavailability of drugs (...) forced patients to purchase from private pharmacies. Informal payments to the health workers may also have increased to offset the lost revenue from fees.

In the long run, policies to replace out-of-pocket payments with health insurance schemes are needed. What will be the place of international NGOs involved in transititional situations in this context?

In September 2009, OXFAM \& Als took an important step, as detailed in their document "Your money or your life" [22] while WHO emphasized the pre-payment from the start [1]. 
Quality improvement methods are not the privilege of peace and development - they also apply in wartime [28] (See Box 6).

From the early stage of the programme, resources are devoted to supervision. Supervision is the link between central (district) and peripheral rural health care delivery, is important for performance and motivation, and may include (a) problem solving; (b) reviewing records; (c) observation of practice (clinical and others) and frequently involves visits to the supervisee's place of work. Fig. (3) illustrates a supervision model.

Box 6. East of the Democratic Republic of Congo 20022004: Quality Improvement for Clinical Examination

One problem that all health supervisors face is how to ensure that regular
and qualitative clinical observation continues to form part of any
consultation.
In 2003 , the ICRC organised a competition between the 14-supported
$\mathrm{HC}$. A first draft of the 'ideal clinical examination' was shared between
all the nurses and clinical officers working in these HCs in the provinces
of Katanga, Oriental, and North and South Kivu. Each participating HC
was asked to suggest amendments to the draft. The winner of the
competition was the HC, which made the best suggestions.
After careful review, inputs in the form of text, drawings and
suggestions were accepted and an official "Clinical examination Guide"
was printed.
A small patient survey confirmed the supervisor's observation that
interest in clinical examination was regained. The guide is still a
standard for supervision.

NGOs will plan supervisions/on the spot training according to distances from the sub-delegation, security conditions, and the diversity of services delivered in the HC.

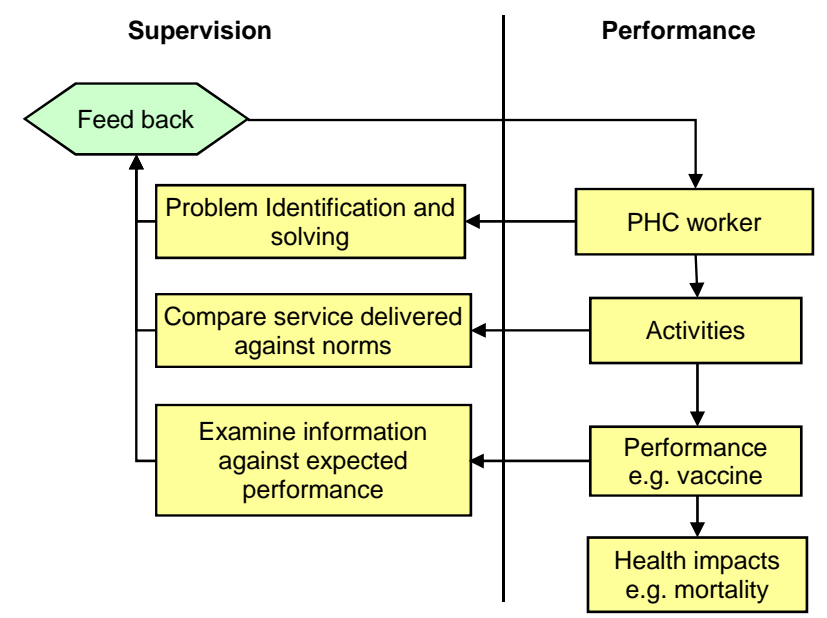

Fig. (3). Management framework for supervision. Source [29]: PHC supervision in developing countries

\section{Community Participation}

The 1978 Declaration of Alma-Ata identifies community participation "as the process by which individuals and families assume responsibility for their own health and welfare and for those of the community, and develop the capacity to contribute to their community's development".

Community-financing or cost-sharing by means of user fees are part of community participation that represents a broader concept involving all possible community nonfinancial strategies [25].

In most developing countries, each PHC should have a health committee and, in accordance with policies, traditional birth attendants (TBAs) and community health workers (CHWs). All these members are volunteers.

The Health Committee is composed of community representatives. In compliance with national policies, they are elected or nominated and are given responsibilities for activities such as social mobilisation, maintaining lists of vulnerable persons, maintenance of the $\mathrm{HC}$, cleaning of compound, cost-sharing management, Essential Drugs management, collection of annual fees for mutual insurance schemes and so on.

Most Traditional Birth Attendants (TBAs) have no formal basic education. They acquire their knowledge through experience. Most countries expect deliveries to be conducted by skilled midwives in maternity units and no longer encourage TBA support. Due to their involvement in crisis-hit areas, some organisations such as the ICRC or UNHCR take a more pragmatic approach. They support existing TBAs to better define when and where to refer expectant mothers when skilled midwives and maternity units are not available. TBAs are the key to swift referral decision-making, but their involvement should not be such that it delays referral. (see Box 7: Liberia).

Community Health Workers are expected to perform a wide range of educational and promotional tasks, such as mobilisation of mothers and their children for vaccination and other services provided at the health centres such as National Immunisation Days. With the support of UNICEF, some of them are trained not only as vaccinators but also as community drug distributors (First-line malaria treatment for the children under 5 years with symptomatic malaria). This has generated confusion, with false expectations both at their level and within the community. From experience, NGOs should support vaccinators only in the context of vaccination programs, and during outbreaks or emergencies.

\section{Box 7. Liberia 2006-2007: Training of Traditional Birth Attendants (TBAs)}

In 2006, The ICRC was supporting $8 \mathrm{HCs}$ in Lofa County Liberia. One of the many problems faced by the $\mathrm{MOH}$ in a country devastated by years of war was the recruitment of qualified midwifery staff to remote HCs. In the light of this ICRC decided to continue to support the training of TBAs. To facilitate this process in collaboration with the $\mathrm{MOH}$ and the community, the following took place:

- From the HC catchment areas the community proposed the names of TBAs to undertake the training

- The MoH in collaboration with the HC in charge conducted interviews and a "pre-test" and made the final decision on the participants for the training

- $\quad$ The community members provided or constructed a suitable building for the training ( near the $\mathrm{HC}$ )

- On commencement of training The NGO midwife in collaboration with the $\mathrm{MoH}$ facilitated the training (based on MoH curriculum)

- Mid term evaluation, post test exam and presentation of results conducted by the $\mathrm{MoH}$

The results of this training were:

- Improvement in the knowledge of the TBAs

- Strengthening of links between the $\mathrm{MOH}$, the community, the $\mathrm{HC}$ and the TBAs. 
Involvement with the various elements of the community requires more methodology, organisation and time than expected. Less educated people require more supervision and follow-up.

Time constraints and high NGO staff turnover are important limiting factors to take into account before embarking on community support. A deep knowledge of community culture and motivation is needed to avoid any potential misunderstanding.

All these community elements should meet monthly at the health centre.

Communication between the PHC, the community and its volunteers is a fragile component of any PHC strategy. The following steps are important factors in liaising effectively and holding successful meetings.

- During the first week of the month, PHC staff members complete the Health Management Information System (HMIS) forms, analyse the data and send the report to the District.

- The Results Illustration Charts are updated for presentation at the community meeting. (key community stakeholders such as the chairperson of the Health Committee and TBA and $\mathrm{CHW}$ representatives).

- The same month, the staff members responsible present and explain the monthly results to the community representatives: Health Committee, TBAs and CHWs. The results are discussed, and mobilisation activities are agreed upon for the CHWs and TBAs (See Box 5 Uganda).

\section{Box 8. Uganda 2007-2010; Monthly Community Meetings}

\begin{abstract}
Lack of human resources is not the only reason for a weak health system in Uganda. The absence of cost sharing, lack of HC supervision and gaps in public health policy are co-factors in a poorly functioning system. Communities are not yet playing an active role in ownership of the HC.

Holding a monthly community meeting with $\mathrm{HC}$ staff and the community (CHW, TBA and the health committee) was introduced in some of the Northern Uganda HCs.

Prior to the monthly meetings, HC staff members analyse the HMIS data for that month and record the results on Result Illustrations Charts (RICs), for example, the number of infants under 1 year receiving measles vaccination.

The health committee or HC staff then chair the meeting which is attended by TBAs, vaccinators and other CHWs.

The meeting is then opened up, offering a democratic approach to health matters. There is room for discussion, exchange of views, explanations and so on, all of which encourages greater accountability from those involved. Objectives are discussed and agreed upon at this meeting, for example, "increased encouragement to mothers to bring their children for vaccination and the importance of vaccination during pregnancy".
\end{abstract}

\section{Monitoring, Evaluating and Learning}

There is a vast amount of peer reviewed literature on monitoring and evaluation available in bookshops and humanitarian internet sites (SPHERE project, ALNAP, IASC ...) [30-32]. However, beyond the theory, decisions are often taken in the field without evidence [33]. Furthermore, community involvement is minimal [25].

The key concepts shared by all NGOs are:
Monitoring is a continuous and systematic process of collecting, measuring, recording, analysing and communicating information intended to aid management. Monitoring encountered in the field are primarily situation, activity and results monitoring.

Monitoring is useful to inform management decisionmaking, to support learning and also to assist internal and external reporting.

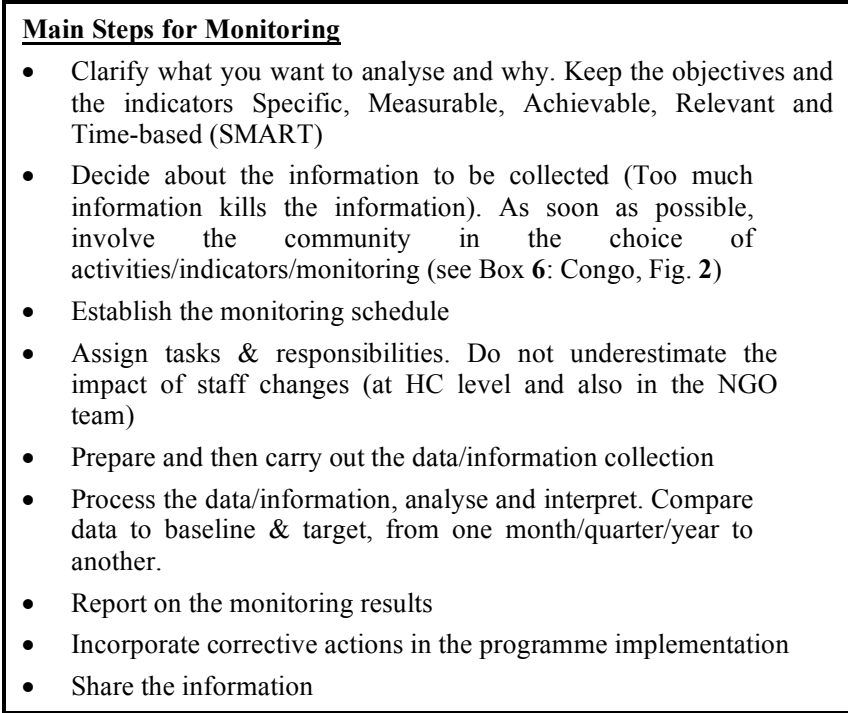

In transitional situations, monitoring is often overlooked at the expense of costly donor-led evaluations [33]. It is important to use the information obtained through the monitoring system as a management tool.

Evaluations are an independent, objective and systematic assessment of the design, implementation and results of a programme (against recognised criteria) intended to draw lessons to improve practice and enhance accountability. Table 3 compares main characteristic of monitoring and evaluation.

Table 3. Monitoring vs Evaluation

\begin{tabular}{|c|c|}
\hline Monitoring & Evaluation \\
\hline \hline A continuous process & At a moment in time \\
\hline $\begin{array}{c}\text { To provide information for day- } \\
\text { to-day decision making } \\
\text { (adjustments or not) }\end{array}$ & $\begin{array}{c}\text { To provide findings, conclusions } \\
\text { and recommendations for strategic } \\
\text { decision-making processes }\end{array}$ \\
\hline $\begin{array}{c}\text { Is carried out by the people who } \\
\text { implement the programme }\end{array}$ & $\begin{array}{c}\text { Is carried out by people who have } \\
\text { not been involved in the } \\
\text { programme. Generally evaluations } \\
\text { are carried out by external people }\end{array}$ \\
\hline
\end{tabular}

Impact evaluations are difficult and costly. It is important to rationalise the use of resources by limiting evaluation to output or outcome, with a clear explanation to donors and decision-makers.

In current practice, the health impact of programmes is too often assumed rather than demonstrated and assessment is seen as a separate activity that takes place at the end of the 
Box 9. East of the Democratic Republic of Congo 2002-2004: Participation by Crisis-Affected Populations in Humanitarian Action

During the civil war that divided the DRC into different rebel-controlled areas, the ICRC was supporting 16 health centres, 5 of which were in Oriental Province. These Ikela health centres were on the front line in RCD-Goma controlled territory, while Ikela itself, with its referral hospital, were on the government side. Support was given from Kisangani, $272 \mathrm{~km}$ away from Ikela, forcing us to organise a relay of volunteers on boats and bicycles. An ICRC Congolese doctor provided a permanent service on a rotating basis to these 5 centres located deep in the rain forest.

According to Congolese culture, "PHC is born in the Congo, before being named in Alma Ata and baptised in Bamako". Indeed, before actually working there, it is difficult to imagine the high level of public health awareness among health staff and in the community.

The following are three examples of indicators developed by HC staff and their health committee. In Ikela district, specific objectives were chosen by HC staff, the committee and the ICRC, and then prioritised with their respective indicators. The "Hygiene Indicator" and the "Pharmacy Indicator" relate to activities carried out by HC staff and monitored by the health committee. The "Health Committee Indicator" relates to committee activities and is checked by HC staff

The hygiene indicator;

\begin{tabular}{|l|l|}
\hline There is a clean and covered latrine within 20 metres of the HC & 1 point \\
\hline Access to the rubbish pit is fenced and the pit is covered or there is an incinerator & 1 point \\
\hline There is no rubbish visible in the HC compound & 1 point \\
\hline Grass is cut and collected in the HC compound & 1 point \\
\hline There is no rubbish visible in the HC (Ground, closet, window sill ) & 1 point \\
\hline The ground is clean and there is Chloramine cleaning twice a week & 1 point \\
\hline The rooms are clear and well-ventilated & 1 point \\
\hline Clean water and soap are available & 2 points \\
\hline All surfaces (Desk, cupboard, shelves...) are clean & 1 point \\
\hline Total & 10 points \\
\hline
\end{tabular}

The pharmacy indicator;

\begin{tabular}{|l|l|}
\hline In the main store, & \\
\hline Medicines are properly ordered, with corresponding updated bin card & 1 point \\
\hline Stock in the store corresponds to that detailed on bin cards & 1 point \\
\hline Medicines are classified and utilised according to expiration date & 1 point \\
\hline A monthly inventory is carried out & 2 points \\
\hline Daily consumption and pharmacy & 1 point \\
\hline Prescriptions and their details in the register match & 1 point \\
\hline Entries in the register correspond to medicines issued from the main store & \\
\hline $\begin{array}{l}\text { Monthly balance detailed in the last column of the register corresponds to } \\
\text { the sum of all entries minus total daily consumption } \\
\text { the visible stock in the pharmacy }\end{array}$ & 1 point \\
\hline Total & 2 points \\
\hline
\end{tabular}

The health committee indicator;

\begin{tabular}{|c|c|c|}
\hline Objective & Indicator & Score \\
\hline $\begin{array}{l}\text { Support the election of a } \\
\text { committee in compliance with } \\
\text { national norms }\end{array}$ & A health committee is elected in compliance national norms & 1 point \\
\hline $\begin{array}{l}\text { Guarantee equality in community } \\
\text { representation }\end{array}$ & $\begin{array}{l}\text { At least } 10 \% \text { of members are women } \\
\text { Distant villages have their own representatives }\end{array}$ & $\begin{array}{l}1 \text { point } \\
1 \text { point }\end{array}$ \\
\hline $\begin{array}{l}\text { Stimulate regular and fruitful } \\
\text { meetings }\end{array}$ & $\begin{array}{l}\text { There is a calendar of monthly meeting } \\
\text { All meetings are held with at least } 75 \% \text { of the members and with minutes taken } \\
75 \% \text { of the decisions taken are applied by the due deadline }\end{array}$ & $\begin{array}{l}1 \text { point } \\
1 \text { point } \\
1 \text { point }\end{array}$ \\
\hline $\begin{array}{l}\text { Reinforce the link between the } \\
\text { HC and the committee }\end{array}$ & $\begin{array}{l}\text { There is a monthly financial audit and careful analysis thereof } \\
\text { Activity inputs and outcomes are analysed } \\
\text { Each new batch of medicines is opened in presence of the committee with records duly completed. } \\
\text { There is a monthly inventory and proper analysis of the contents of the main store. }\end{array}$ & $\begin{array}{l}1 \text { point } \\
1 \text { point } \\
1 \text { point } \\
1 \text { point }\end{array}$ \\
\hline & Total & 10 points \\
\hline
\end{tabular}


project $[33,34]$. The impact-related indicators (mortality rate, under age 5 mortality rate and nutrition status) relating to the programme's aim in Table $\mathbf{1}$ is best checked before and during programmes by means of regular surveys [35].

Fig. (5) illustrates monitoring and evaluation in relation with our activities, objectives and desired impact.

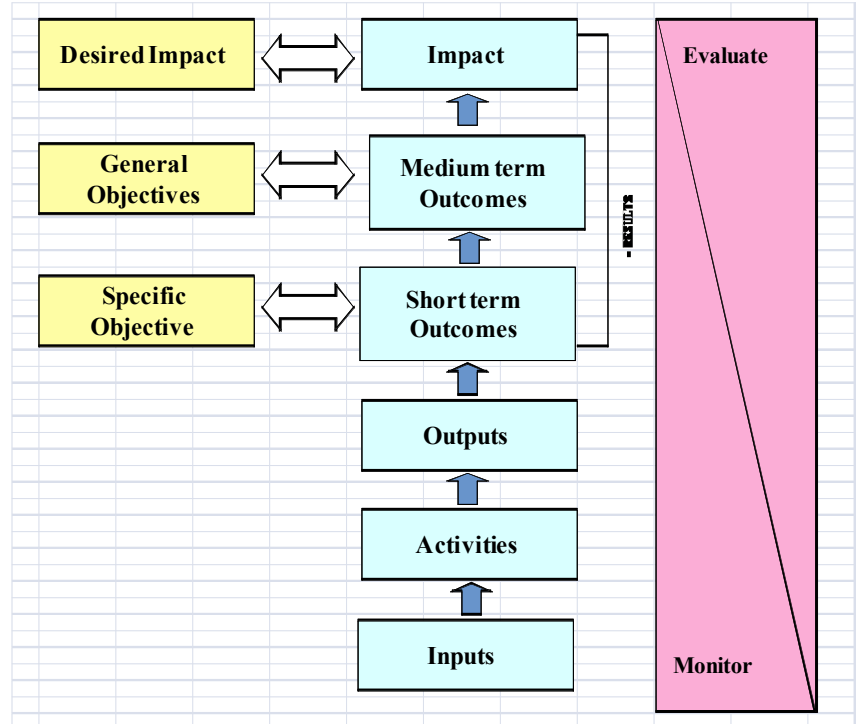

Fig. (4). Monitoring the activities and evaluate the impact.

Indicators help to demonstrate change in conditions or results linked to interventions and provide evidence of progress. Table 1 provides a modest yet practical list of indicators corresponding to each SO.

The main challenge in transitional situations is to identify when to leave, according to results captured by indicators. One way is to compare the results of supported PHC centres with national results and international norms. These indicators are not only related to service delivery (e.g. vaccination coverage) but also to management (e.g. number of paid staff, regularity of medicine refurbishment), or security issues.

\section{CONSTRAINTS ENCOUNTERED}

The main field constraints described by the NGOs are:

MoH weaknesses:

- Limited human resources at district level, and especially at HC level.

- Authority of the district team is weak and control of PHC staff is limited, leading to absenteeism. Limited interest in methodology due to multiplicity of partners.

- Absence of constructive supervision despite programme opportunities.

NGOs do not provide systematic and harmonised health training for their staff.

High staff turnover jeopardises quality follow-up and consistency.

International variations in standard training: education levels among NGO local staff and also PHC staffs vary widely according to their background (See Fig. 5).
Many stakeholders support vertical programmes, while few partners have a comprehensive approach.

Some implement only the immunisation programme or the gender violence programme with no integration with other services. For very specific programmes such as prevention of vertical transmission, this is an advantage.

To avoid duplication, some NGOs have withdrawn their support from some PHC when there is overlap with the programmes of other partners. Avoiding duplication is one of the roles of national authorities, with the support of the WHO in coordinating matters through the health \& nutrition cluster.

As already mentioned, exit strategies are likely to be successful where the health system is supported by development partners.

Continuity of care is difficult to ensure due to lack of transport/ambulance services in most countries in transition situations. Assistance to referral hospitals is a factor that cannot be overlooked within PHC support.

UN or ECHO funded NGO may have difficulties in guaranteeing the continuity of their presence for the following year. This, of course, jeopardizes any smooth transition. The exist strategy is continually discuss to ensure that all options are considered, such as NGO replacement or renegotiation of the exit strategy itself.

\section{DOCUMENTATION OF THE RESULTS}

Requirements by the donors (ECHO, USAID, UNHCR, World Bank...) the documentation of results are commonly understood as a compulsory tool for further adjustment of the programmes.

While national formats take priority, each NGO has its own reporting formats. The following chapter documents some examples of useful supports for documenting activities and regularly assessing the situation.

Most of the countries concerned have a regional/national HMIS. The HMIS is not only the epidemiological report for clinical activities but is also a Health Management Information System incorporating management indicators. It is essential that the NGOs do not develop a system that parallels that already existing in the country before the crisis. Resources and time should be focused on the best use and analysis of local data.

Most of the countries have an Early Warning System. In this report, only communicable diseases with potential outbreaks are reported on a daily or weekly basis (Cholera, Dysentery, Measles, Meningitis, Hepatitis, etc).

If the Early Warning System does not exist or is not in operation, it is essential to put one in place, in collaboration with the $\mathrm{MoH}$ and other NGOs. The means of transmitting such data must be faster and more efficient than the monthly HMIS in order to generate daily (in case of an outbreak) or weekly actions.

A common tool found at the level of the $\mathrm{HC}$ is the Results Illustration Chart (see Fig. 5). These charts illustrate the monthly achievement of the health centre to obtain quantified results. The objectives target a specific population living in the catchment area. From existing demographic 
information, the PHC manager should obtain a clear idea of the different target groups, such as $<1$ year old, $<5$ years old, $<15$ years old, pregnant women, over 60 years old.

According to the different specific objectives (SOs) chosen at HC level, the PHC manager draws up the chart based on examples found below (see Table 1).

New consultations are reported monthly, and cumulative counts performed and documented.

This document is useful as a visual tool to illustrate the trend of services provided over a 12 month period but also at the PHC level to ascertain their achievement level, and to enable the team to adapt and provide course correction changes in a timely manner to attain the objectives. During the monthly meeting with the community, these charts are used to exchange information with CHWs and TBAs who are key social mobilisers in deciding the priorities for the months to come. NGOs also use them as daily, weekly, and monthly briefing templates to better communicate vital information to interested partners and stakeholders, and to document challenges and successes.

A simple tool used by ICRC is the morbidity based report (See Table 4). The aim of this report is to document in tabular form the different activities performed to prevent and treat the main pathologies in each $\mathrm{HC}$.

Other pathologies documented may include diarrhoeal disease, moderate malnutrition, STI, skin conditions etc.

The pathologies are ranked according to their prevalence. Examples of activities required to tackle these diseases are shown in the second column of the table. They are drawn up according to $\mathrm{MoH}$ norms and WHO packages.

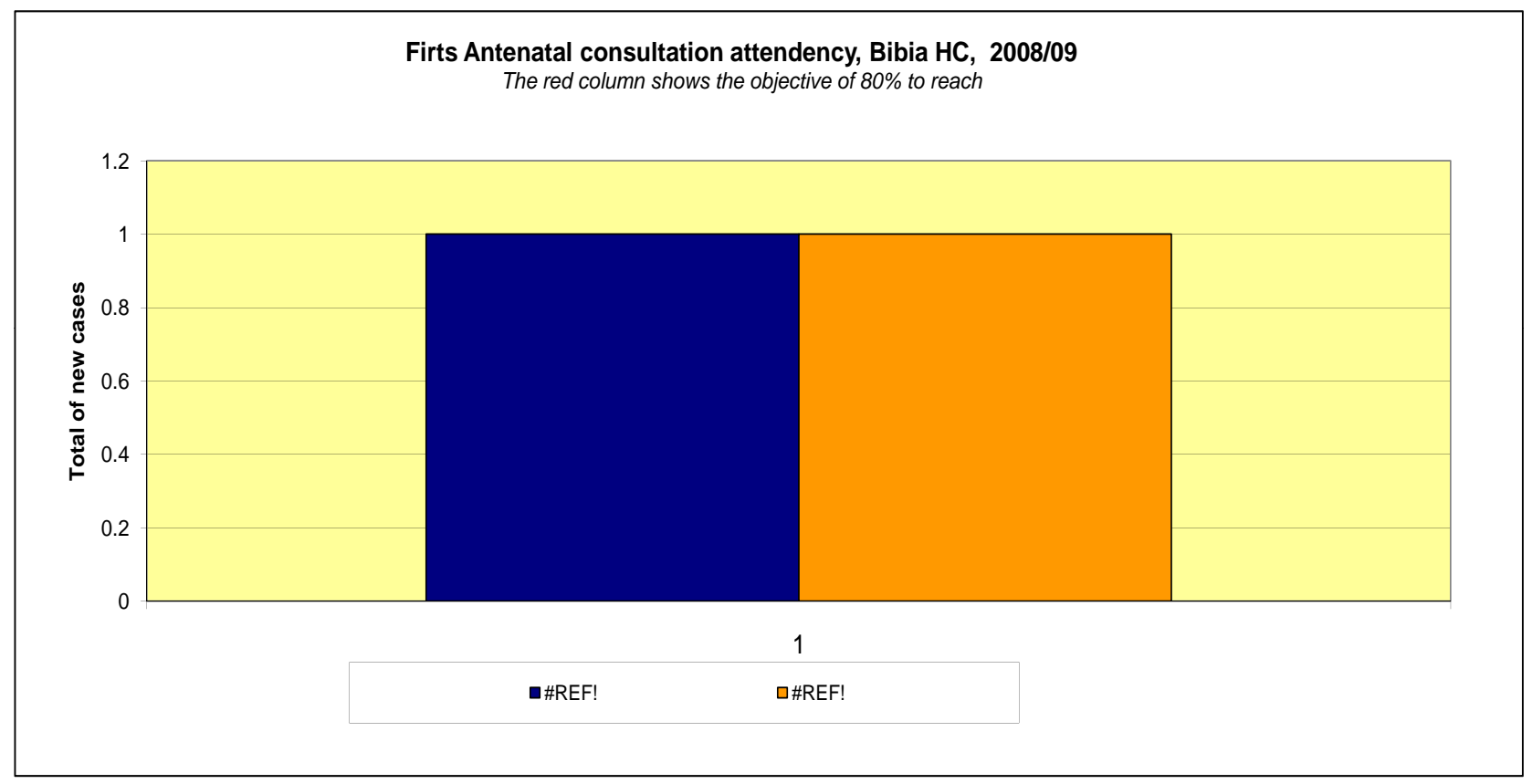

Fig. (5). An example of Results Illustration Chart in Uganda.

Table 4. Morbidity-Based Report

\begin{tabular}{|c|c|c|c|c|}
\hline Main Causes of Morbidity & Main Activities & Bibia HC & Pawel HC & XX HC \\
\hline \multirow{8}{*}{ Malaria } & Environmental control. & & & \\
\hline & Indoor Residual Spraying & & & \\
\hline & Mosquito net distribution & & & \\
\hline & Intermittent Presumptive Treatment & & & \\
\hline & Mosquito net during pregnancy & & & \\
\hline & Rapid Diagnostic Test & & & \\
\hline & Compliance with national protocols & & & \\
\hline & Availability of Treatment & & & \\
\hline \multirow{3}{*}{ Acute Respiratory Tract Infections } & Early diagnosis & & & \\
\hline & Compliance with protocols & & & \\
\hline & Availability of treatment & & & \\
\hline
\end{tabular}


Table 5. Performance Table

\begin{tabular}{|c|c|c|c|c|c|}
\hline \multicolumn{6}{|c|}{ Bibia HC - October 2008} \\
\hline $\begin{array}{l}\text { Service Based } \\
\text { Objectives }\end{array}$ & $\begin{array}{l}\text { Indicators and } \\
\text { Measurement Method }\end{array}$ & $\begin{array}{l}\text { Date of Initial Measurement } \\
\text { and Value }\end{array}$ & $\begin{array}{l}\text { Indicator } \\
\text { Targeted Value }\end{array}$ & $\begin{array}{l}\text { Indicator Value in } \\
\text { October } 2008\end{array}$ & Remarks/Actions Taken \\
\hline \multirow[t]{2}{*}{$\begin{array}{l}\text { Antenatal clinics } \\
\text { are held in } \\
\text { compliance with } \\
\text { national norms. }\end{array}$} & $\begin{array}{l}\text { Percentage of pregnant } \\
\text { women attending ANC } 1 \\
\text { (HMIS form) }\end{array}$ & January $2007 ; 12$ ANC1 only & $\begin{array}{l}\text { At least } 25 \mathrm{ANC1} / \\
\text { month, } 300 \mathrm{ANC1} / \\
\text { year }\end{array}$ & 28 ANC 1 & $\begin{array}{l}80 \% \text { of the pregnant women in } \\
\text { the catchment area ( } 300 \text { a year, } 25 \\
\text { a month). }\end{array}$ \\
\hline & $\begin{array}{l}\text { Percentage of woman who } \\
\text { received Fansidar twice } \\
\text { during pregnancy (HMIS } \\
\text { form) }\end{array}$ & $\begin{array}{l}\text { January 2007; } 8 \text { Fansidar } 2 \\
\text { only }\end{array}$ & $\begin{array}{l}\text { At least } 25 / \text { month, } \\
300 / \text { year }\end{array}$ & 24 IPT2 & $\begin{array}{l}80 \% \text { of the pregnant women in } \\
\text { the catchment area ( } 300 \text { a year, } 25 \\
\text { a month) }\end{array}$ \\
\hline $\begin{array}{l}\text { Family planning } \\
\text { consultations are } \\
\text { held regularly }\end{array}$ & $\begin{array}{l}\text { Percentage of women } \\
\text { accessing FP consultations }\end{array}$ & July 2007 ; only 2 & At least $31 /$ month & $\begin{array}{l}11 \mathrm{FP} \text { consultations } \\
\text { only }\end{array}$ & $\begin{array}{l}30 \% \text { of the women of } \\
\text { reproductive age ( } 380 \text { a year, } 31 \text { a } \\
\text { month) }\end{array}$ \\
\hline
\end{tabular}

Using these tables encourages the team to reassess, on a quarterly basis, the implementation of essential activities for each HC supported.

Other shared tools are the performance tables which may be designated differently from one NGOs to another (See Table 5). The table documents the progression of the programme by specific objectives, for each HC that is supported.

It is a useful table to complete on a monthly basis, ideally involving the PHC clinician in charge, the health committee and the NGO. When it is not possible to have the collaboration of the clinician or the health committee, the SO follow-up report remains an internal document.

The SO table documents some of the results and problems illustrated by the Result Illustration Chart, but it can also be used to identify the successes and challenges in other areas such as community involvement, management and maintenance. The indicators reported are provided in Table $\mathbf{1}$.

Ideally, the indicators are agreed at PHC and community level and should be checked by health committee members or the clinician in charge (See Fig. 2).

Even if revised within 4 to 6 weeks, this report is edited quarterly for documentation purposes.

\section{CONCLUSION}

Although most emergency NGOs have proved effective in acute crisis situations, with service delivery driven emergency action carried out without question, the difficulties encountered in transition situations are sources of concern, and the transition situation decision-making process rests on a wider set of variables, including local technical capacity to manage.

After any crisis there must be an assessment and analysis of needs, stakeholders' agendas, local capacity and community involvement. A longer timeframe must be envisaged to include local capacity building. Regular re-scheduling might be needed depending on a volatile security situation, any limitations on the actions of the various partners or authorities experiencing difficulties in shouldering their responsibilities. Involving a weakened local population and/or demotivated health workers is always difficult.

Rapid turnover in health staff and short-term planning for the use of annual donations are two key constraints that need to be understood. It is easier to find human resources and raise funds for a crisis that attracts major international media coverage (for example, tsunamis or earthquakes) than for chronic or transitional situation crises in forgotten areas (Darfur, DRCongo or Rohinga, stateless populations in Bangladesh and Myanmar). Both the donor community and the media need to balance their coverage and their analyses of such situations.

Together with this longed-for shift in donor and news coverage patterns, humanitarian organisations rightfully question their actual capacity to address longer-term challenges, where time and grass roots level involvement are essential. Working towards sustained development is a serious matter requiring long-term commitment. It should be based on sound management tools and the sort of community involvement approach that has been highlighted in this article. The authors contend that the framework this article provides will assist decision-makers in choosing the appropriate services and approach to best meet the needs of the populations they support in transition situations.

Maximising the beneficial effects of interventions in transition situations involves being aware of development and reconstruction requirements as early as possible in the crisis. At a local level, any organisation's humanitarian work is also part of rebuilding the social fabric that has been torn apart.

Any crisis brings a burden of destruction and suffering. The only positive effect it may have is to engender social changes and expose the affected society to new approaches and tools, and thereby offer better prospects. The same applies in the health sector. Transition situations are an excellent opportunity for introducing good practice and quality service, which may not have been present before the crisis.

Taking into account the large body of literature that has been produced on supporting health systems in transition and postconflict situations, and recognising the imperative need to improve access to and the quality of services, this paper presents a grass roots level, practical managerial tool for key steps in pragmatic decision-making in health care provision.

\section{ABOUT THE AUTHORS}

Stéphane Du Mortier has worked as a doctor with the Belgian Red Cross, the International Committee of the Red Cross (ICRC) and the United Nations (UNV-UNDP). He is 
currently working in Iraq. His contact is stephdumortier@hot mail.com

Ruth Bullen is a Registered Nurse and Midwife from the UK. She has worked in Australia for the Royal Flying Doctor Service and was an Immunisation Coordinator in North Queensland for the Queensland Health Department. After missions for the British Red Cross she is today working as a Maternal and Child Health Coordinator in North Queensland. Her contact is bullen193@hotmail.com

Hervé le Guillouzic is a Humanitarian Medical Doctor with 22 years of field and coordination experience in emergencies, transition and development throughout Africa and Asia. He has worked with MSF, the Red Cross Movement, the UN and bilateral development agencies (USAID, EC) to strengthen health services in fragile settings. His contact is le.guillouzic@gmail.com

\section{ACKNOWLEDGEMENT}

Frederick M. Burkle, Jr., MD, MPH, DTM, Senior Fellow \& Scientist, Harvard Humanitarian Initiative, Harvard School of Public Health, Cambridge, MA, USA.

\section{REFERENCES}

[1] WHO World Health Report 2008: primary health care, now more than ever. Available from: http://www.who.int/whr/2008/whr08_ en.pdf

[2] Burkle FM Jr. Future humanitarian crisis: challenges for practice, policy, and public health. Prehosp Disaster Med 2010; 25(3): 1919.

[3] Harroff-Tavel M. The transition from acute to chronic in medicine and in the humanitarian work of the ICRC. Int Rev Red Cross 2008; 851: 465-96. Available from: http://www.icrc.org/web/ eng/siteeng0.nsf/html/assistance-feature-200308

[4] Van Damme W, Van Lederberghe W, Boelaert M. Primary health care $v s$ emergency medical assistance: a conceptual framework. Health Policy Plan 2002; 17(1): 49-60.

[5] Médecins Sans Frontières: refugee health, an approach to emergency situations. Macmillan: UK 1997.

[6] Perrin P. Primary health care services. Geneva: ICRC 2006.

[7] Du Mortier S, Coninx R. Mobile health units in emergency operations, a methodological approach. HPN 2007, Network paper Nr 60. Available from: http://www.odihpn.org/report.asp?id=2895

[8] WHO. Rapid health assessment protocols for emergencies. Geneva: WHO 1999.

[9] Redmond AD. Needs assessment of humanitarian crisis. BMJ 2005; 330: 1320-2.

[10] Coupland R. Security, insecurity and health. Bull World Health Organ 2007; 85: 181-4.

[11] Checchi F, Roberts L. Interpreting and using mortality data in humanitarian emergencies, a primer for non-epidemiologists. HPN 2005, Network paper $\mathrm{Nr}$ 52. Available from: http://www.odihpn. org/report.asp?id $=2702$

[12] Checchi F, Gayer M, Freeman RG, Mills EJ. Public health in crisisaffected populations: a practical guide for decision-makers. HPN 2007, Network paper Nr 61. Available from: http://www.odihpn. org/report.asp?id $=2902$

[13] Thieren M. Health and foreign policy in question: the case of humanitarian action. Bull World health Organ 2007; 85: 218-24.
[14] Raise Initiative. Minimum Initial Service Package (MISP). Available from: http://www.raiseinitiative.org/library/pdf/fs_misp. pdf

[15] UNHCR. Principles and guidance for referral health care for refugees and other persons of concern. GVA, 2009. Available from: http://www.unhcr.org/4b4c4fca9.html

[16] Poletti T. Healthcare financing in complex emergencies. A background issues paper on cost-sharing. HPN 2004. Network paper $\mathrm{Nr}$ 26. Available from: http://www.odihpn.org/report.asp? id $=2609$

[17] Arhin-Tenkorang D. Mobilizing resources for health: the case of user fees revisited. CID working paper 2001. Available from: http://www.hks.harvard.edu/var/ezp_site/storage/fckeditor/file/pdfs /centers-programs/centers/cid/publications/faculty/wp/081.pdf

[18] Bitrán R, Giedion U. Waivers and exemptions for health services in developing countries. World Bank 2003: Social Protection Discussion Paper Series, No. 0308. Available from: http://site resources.worldbank.org/SOCIALPROTECTION/Resources/SP-

Discussion-papers/Safety-Nets-DP/0308.pdf

[19] Gilson L. The lessons from user free experience in Africa. Health Policy Plan 1997; 12: 273-85.

[20] Burnham G, Pariyo G, Galiwango E, et al. Discontinuation of cost sharing in Uganda. Bull World Health Organ 2004; 82(3): 187-95.

[21] Xu K, Evans DB, Kadama P, et al. Understanding the impact of eliminating user fees: utilization and catastrophic health expenditures in Uganda. Soc Sci Med 2006; 62: 866-76.

[22] OXFAM International .The money or your life. Oxfam 2009. Available from: http://www.oxfam.org/en/policy/your-money-oryour-life

[23] The SPHERE Project. Humanitarian charter \& minimum standards in disaster response. London: S Print \& redesign 2004.

[24] World Health Organization. Action programme on essential drugs how to investigate drug use in health facilities: selected drug use indicators. Geneva: WHO 1993.

[25] ALNAP. Participation by crisis-affected populations in humanitarian action. Handbook for practitioners. ALNAP 2003. Available from: http://www.alnap.org/pool/files/gs_handbook.pdf

[26] Massoud R, Askov K, Reinke J, et al. A modern paradigm for improving healthcare quality. QA Monograph Series 2001; 1(1). Available from: http://www.qaproject.org/pubs/PDFs/improhq601 bk.pdf

[27] MSF hospital policy (2008) internal document, unpublished.

[28] Du Mortier S, Arpagaus M. Quality improvement programme on the frontline: an ICRC experience in the Democratic Republic of Congo. Int J Qual Health Care 2005; pp. 1-8.

[29] Bosch-Capblanch X, Garnier P. Primary Health care supervision in developing countries. Trop Med Int Health 2008; 13(3): 369-83.

[30] Roberts L, Helderman T. Priority indicators in complex emergencies, summary of a consultancy for the health and nutrition tracking system. HTNS 2008. Available from: www.who.int/entity/ hac/techguidance/hnts/hnts_priority_indicators.pdf

[31] ALNAP. 2003. Annual review 2003. Strengthening monitoring in the humanitarian sector. Available from: www.alnap.org/resour ce/5199.aspx [cited: Sept $1^{\text {st }}$ 2010].

[32] Hallam A. Evaluating humanitarian assistance programmes in complex emergencies. HPN 1998, Good practice review $\mathrm{Nr} 7$. Available from: http://www.odihpn.org/report.asp?ID=2109

[33] Roberts L, Hofman CA. Assessing the impact of humanitarian assistance in the health sector. Emerg Themes Epidemiol 2004; 1: 3.

[34] Roberts L. Advances in monitoring have not translated into improvements in humanitarian health services. Prehosp Disaster Med 2007; 22(5): 384-9.

[35] Spiegel PB. Who should be undertaking population-based surveys in humanitarian emergencies? Emerg Themes Epidemiol 2007; 4: 12 . 